\section{Habits of Dogs.}

IN reply to Dr. Kidd's question as to the disposition of dogs to carry hedgehogs in their mouths, I may say that a smooth-haired Irish terrier, "Tim," of which I had charge for some weeks in the early spring of the present year, speedily became an expert hunter of hedgehogs, and carried home five living ones in the course of a month. I am inclined to think that he came upon the first one in its winter quarters quite by chance; but on almost every subsequent occasion, when taken out for a run after dark, he quickly disappeared amongst the gorse and ling, and, eluding my daughters, returned home alone with a hedgehog in his mouth. On one occasion he had cunningly bitten off the ends of a number of the spines on the back of his captive, and on only one occasion did I see blood upon his lips. H. C. CHadwick.

The Biological Station, Port Erin, Isle of Man, September 16.

With reference to the letter of Mr. Venables in Nature of September 2I, it may interest your correspondent to know that the stimulation from formic acid taken by the mouth is " out of proportion to the effect which one would expect from the mere acidity."

Formic acid is given in medicine for states of debility, e.g. following influenza, and a tincture made from the whole ant (Formica rufa) is given in homoeopathy for certain nervous and rheumatic states.

H. Fergie Woods.

“Appledore," Park Drive, Golders Hill, N.W., September 25 .

THE TURIN MEETING OF THE INTERNATIONAL ELECTROTECHNICAL COMMISSION.

THE fourth meeting of the International Electrotechnical Commission was held at Turin, and came to a close on September I6. For several reasons this meeting has established an international interest, not only for electrical engineers, but for mathematicians, engineers, and all interested in the standardisation of symbols used in mathematical literature and formulæ.

The opening business of the meeting consisted in the election of a new president; Dr. Budde, until recently the head of Messrs. Siemens and Halske, of Berlin, and probably the best known of the electrical engineers of Germany, was unanimously elected to fill the position in place of the retiring president, the eminent American physicist, Prof. Elihu Thomson. Colonel Crompton was re-elected as honorary secretary on the proposal of Prof. Feldmann, of Holland, who, in putting forward his proposal, referred to the St. Louis Congress of 1904 , and the part Colonel Crompton took in urging the advisability of international cooperation in matters electrical. He said that Colonel Crompton was, in fact, the father of the International Electrotechnical Commission.

It was extremely satisfactory to note that Dr. Budde's election was proposed by the French delegates, which shows that at any rate any political differences which may exist between France and Germany do not extend to the more serene atmosphere of the scientific world.

The proceedings were formally opened by the reading of a report by the honorary secretary, Colonel Crompton, on the progress of the work since the last formal meeting, and more particularly since the informal meeting which took place at Brussels last year. He pointed out that whereas in Igo8 there were only ten countries taking part in the Commission there were now twenty-one countries subscribing, each of which had formed its own local electrotechnical committee, in most cases with the direct aid of their respective Governments, and he thought it practically NO. 2 I87, VOL. 87$]$ certain that at least three or four other countries were on the way to join, so that the movement might be called practically universal.

Prof. Elihu Thomson then gave an address as retiring president, and described the work carried out at the Brussels informal conference, and advocated that the work of the central office in London would be much lightened by the formation of a few international subcommittees additional to the one which already existed. He pointed out that the subject which required such continuous treatment by an international subcommittee was that of the standardisation of nomenclature and symbols used by mathematicians, engineers, and others, dealing with electrical questions, and he thought that the same might apply to the question of illumination as it was most desirable that the engineers engaged in illumination, not only by electricity, but by other means, should also standardise the expressions and formulæ thev use. He emphasised the need of conducting the work of the Commission so that it may be a material assistance to the electrical industry, and so as not to retard progress or design in any way.

Two days were occupied by unofficial meetings dealing with the business in hand. A report on nomenclature was presented by Dr. Budde, the newly elected president, and after considerable discussion the amended list of terms and definitions drawn up in the two official languages of the Commission-English and French-was provisionally adopted. This list had been prepared by a subcommittee at a conference held at Cologne last May, and was thoroughly discussed and finally adopted at this meeting.

The next and very important matter was that of mathematical symbols. Here again the proposals put forward at the unofficial congress held at Brussels in Ig Io were discussed, somewhat modified, and provisionally adopted; and a resolution was proposed by Dr. Budde, and seconded by Mr. Alexander Siemens, the president of the Institution of Civil Engineers of London, that the letters "I," "E," and "R" should be adopted to represent current, electromotive force, and resistance respectively in the simple algebraic expression of Ohm's law. It will be seen that in coming to this decision concessions were made by Germany dropping the letter "W" for resistance, and by Great Britain discontinuing the letter " $\mathrm{C}$ " for current. It is evident that this agreement on the symbols emploved in Ohm's law will be a great convenience to all electrical students.

The discussion on symbols was a very thorough one, and the difficulties that appear likely to arise, at any rate amongst electrical engineers, are comparatively small compared with the difficulties of selecting suitable signs on account of the limited range of the type letters suitable for the purpose. For magnetic quantities either Gothic, Script, heavy-faced, or any special tvoe was decided upon.

Although the matter was not in any way discussed at the conference, it appears likely that this difficulty could best be met by the substitution of a number of new symbols not necessarily representing letters of any tvpe, but of a form and shape that they could be easily remembered and recognised, and which would be free from the present existing difficulty of causing areat trouble to the composer in setting up his type and spacing his lines.

Eventuallv a subcommittee, consisting of one member each from Belgium. France, Germany, Great Britain, Holland, Spain, Switzerland, and the United States was appointed to continue the study of these international symbols.

The next interesting point dealt with was the vector diagrams in use for alternating-current quantities. It 
was agreed that in the graphical representation of alternating magnetic quantities advance in phase should always be represented in the counter-clockwise direction; in other words, the rotation of the vector should be to the left.

On the question of rating of electrical machinery and apparatus the proposals of the Brussels conference were adopted without modification as follows :-

I. The output of electrical generators is defined as the electrical power at the terminals.

2. The output of electrical motors is defined as the mechanical power at the shafts.

3. Both the mechanical and the electrical power are to be expressed in international watts.

In this work careful attention had to be given to the exact choice of the equivalent words in the two official languages. The convenient word "output" employed by English-speaking nations has no exact equivalent in French. In this case again a subcommittee, consisting of one member from those international committees interested in the subject was appointed to carry on further this question of the international rating of electrical machinery and apparatus.

It was decided that the next meeting of the Commission should be held in Berlin in 1913 , the exact date to be announced later.

Mr. Gano Dunn, the president of the American Institution of Electrical Engineers, invited the Commission to hold an official meeting at San Francisco in I9 $\mathrm{I}_{5}$, on the occasion of the opening of the Panama Pacific Exhibition. On the motion of Prof. Feldmann, of Holland, seconded by Mr. W. Duddell, of England, the meeting thanked Mr. Dunn for the invitation, and stated its willingness to hold a meeting in San Francisco in $\mathrm{Igr}_{5}$, and instructed the Central London Office to cooperate with the American Society in the organisation of an international electrical congress to be held at the same time.

It is interesting to remark that at the meetings of the Electrical Congress, which was sitting at the same time, it was decided that for the future the irregular method of summoning international congresses at the time of the international exhibitions should be discontinued, and that in all cases where such exhibitions were held the International Electrotechnical Commission should be the body which should be invited by the country holding the exhibition to organise the electrical congresses, and in this way avoid much clashing and waste of effort.

Finally, the honorary secretary of the Illuminating Engineering Society of . London, Mr. Leon Gaster, who was nersonally invited to attend this meeting at the invitation of the president. referred at some length to the desirability of standardising the terms and expressions used in connection with illumination. As stated above, this matter was dealt with bv Prof. Elihu Thomson in his address. Mr. Gaster gave very cogent reasons why the present loose methods of expressing standards of light and of measuring these same standards should be discontinued, and that it was inst as desirable in this kindred science of illumination that all nations should understand one another, as in the case of the electrical art and industrv. $\mathrm{Mr}$. fraster's suggestions were strongly supported by Dr. Kennelly and Dr. Clayton Sharp, who are president and past president respectivelv of the Illuminating Society of the United States, and the suggestion that the various national committees be requested to but themselves in rommunication with their respective illuminating societiss was unanimouslv adopted.

There is no dnubt that at this full meeting of the International Electrotechnical Commission during the week in which the delegates worked together much international courtesy was shown, a great many pleasant friendships were made, and undoubtedly everv additional international meeting of the kind greatlv helps on the cause of solidarity between men of science of the world. The meeting room certainly contained a collection of men second to none in the electrical world for intellectual capacity; and that the meeting passed off so smoothly and so much work was done in a comparatively short time showed that the selectors of the delegates had also considered their diplomatic aualities, which had also been carefully studied by the countries which had sent them to the meeting.

\section{PLANTS OF COAL-MEASURES.'}

THE fossil flora of the Upper Carboniferous rocks of Belgian Hainaut is in many respects similar to that of our British coal measures, though many species occur in Belgium which are unrecorded from Britain and vice versa. Those who are interested in the systematic study of British Carboniferous plants

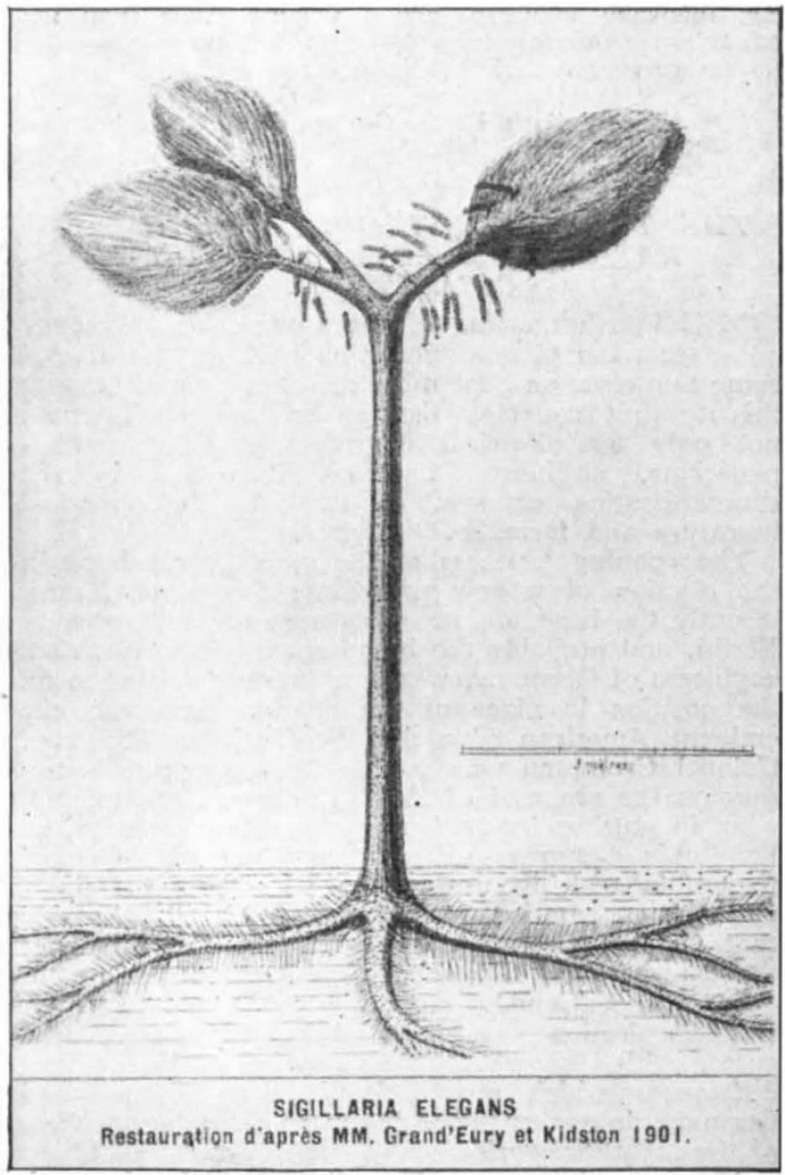

will therefore find much that is of interest in Dr. Kidston's description of the collections, preserved in the Brussels Museum, from this coalfield. In all, 19I species, included in more than fifty genera, are enumerated. It is scarcely necessary to add that the author's high reputation for the accuracy of his deter-

1 Extrait des Mémoires du Musée royal d'Histoire naturelle de Belgique. Tome iv, "Les Végétaux Houillers recueillis dans le Hainaut Belge et se trouvant dans les Collections du Musée royal d'Histoire naturelle à Eruxelles," By Dr. R. Kidston, F.R.S. Année 1909. Pp. iv +282 广 xxiv plates. (Bruxelles: Polleunis et Centerick, rgrr.) 